\title{
Kinematic Analysis of Crank Shaft for Diesel Engine
}

\author{
Maung Maung Yi \\ Department of Mechanical \\ Engineering, \\ Technological University \\ Thanlyin, Myanmar
}

\author{
Su Yin Win \\ Department of Mechanical \\ Engineering, \\ Technological University \\ Thanlyin, Myanmar
}

\author{
Thwe Thwe Htay \\ Department of Mechanical \\ Engineering, \\ Technological University \\ Thanlyin, Myanmar
}

\begin{abstract}
As the crankshaft is subjected to complex bending shear and twisting loads, it needs to be well designed and manufactured in good quality material to withstand the stress. As these stresses may change in direction and magnitude as the crankshaft rotates. In the balancing of the crankshaft, it needs to consider both the static balancing and dynamic balancing. In design calculation of crankshaft kinematics of crank gear, indicator diagram, force acting on the crankshaft and torque acting to the major journal and crank pin are important. The influence of the forces due to inertia both the reciprocating and rotating masses must be taken into account as accurately as possible, especially for high speed. The engine is four cylinders, four-stroke engine, and compression ratio is 20 . The maximum power output of the shaft is $70.4 \mathrm{~kW}$ at $3200 \mathrm{rpm}$. The crankpin diameter and length are $56 \mathrm{~mm}$ and $31 \mathrm{~mm}$, the main journal diameter and length are $65 \mathrm{~mm}$ and $32 \mathrm{~mm}$. The operating conditions of cranks gear elements characterized by the forces which appear in them at various engine duties.
\end{abstract}

Keywords: velocity, gas pressure, inertia force and net force

\section{INTRODUCTION}

The crankshaft serves as the main rotating members, or shaft of the engines. The main function of the crank shaft is charging reciprocating motion to rotary motion. The crankshaft has offset journals to which the connecting rods are attached; it converts their up and down motion into rotary motion. It withstands bending stresses and torsional stresses during the whole time of operation. The connecting rod is connected to the piston by piston pin and to the crankshaft by the crankpin the output end of the crankshaft has flywheel. The front end has the gear or sprocket that drives the crankshaft, the vibration damper and the drives-belt pulley. Central crank gear is as shown Figure 1.

\section{KINEMATIC of CRANK GEAR}

The operation condition of the crank gear element are characterized by the forces which appear in them at various engine duties. The magnitude and the nature of the change of the mechanical loads taken by these elements are determined from kinematic and dynamic investigations of the crank gear. In many modern engine are piston pin axis is offset by 0.01 to 0.03 of its diameter from the cylinder axis in order to achieve continuous elimination of the clearance between the piston and the cylinder wall and the more favorable distribution of load on the piston wall. The ratio between the crank radius and the connecting rod length is assigned.

$$
\begin{aligned}
& \lambda=\frac{\mathrm{R}}{\text { Load }} \\
& \mathrm{k}=\frac{\mathrm{a}}{\mathrm{R}}
\end{aligned}
$$

The piston travel can be calculated

$$
\mathrm{s}=\mathrm{R}\left[(1-\cos \phi)+\frac{\lambda}{4}(1-\cos 2 \phi)-\mathrm{k} \lambda \sin \phi\right]
$$

The piston velocity can be calculated

$\mathrm{V}_{\mathrm{p}}=\mathrm{R} \omega\left(\sin \phi+\frac{\lambda}{2} \sin 2 \phi-\mathrm{k} \lambda \cos \phi\right)$

The acceleration of the piston is

$\mathrm{A}=\mathrm{R}(\cos \Phi+\lambda \cos 2 \Phi+\mathrm{k} \lambda \sin \Phi)$ $\mathrm{a}=$ displacement of the plane of travel of the piston pin axis from crankshaft axis

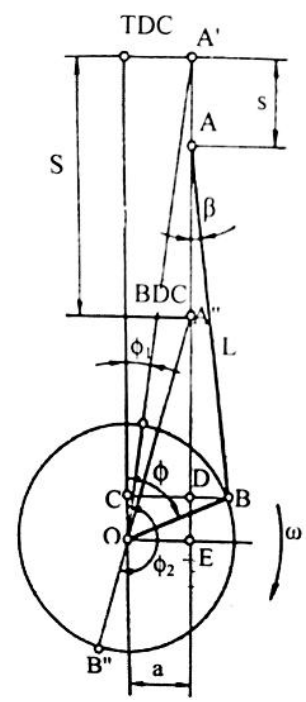

Figure 1.The offset engine crank gear

$\Phi=$ angle of crank travel counted from the cylinder axis in the direction of clockwise crankshaft rotation

$\beta=$ angle between the connecting rod and cylinder axis

$\omega=$ angular velocity of crankshaft rotation

$\mathrm{S}=2 \mathrm{R}=$ piston stroke

$\mathrm{L}_{\text {Rod }}=$ connecting rod length

$\mathrm{V}_{\mathrm{p}}=$ piston velocity

$\mathrm{A}=$ acceleration of the piston

Take the rotational speed of engine $\mathrm{N}=3200 \mathrm{rpm}$ and the offset is $0.015 \mathrm{D}$ [2]. Piston-travel, velocity and acceleration with corresponding crank angle are shown in Table 1.

where,

$\mathrm{R}=$ crank radius

$\lambda=$ dimensionless parameters

$\mathrm{k}=$ the relative displacement 
Table 1. Piston travel, velocity, acceleration with corresponding crank angle

\begin{tabular}{|l|l|l|l|}
\hline Degree & $\begin{array}{l}\text { Piston } \\
\text { travel }\end{array}$ & Velocity & Acceleration \\
\hline 0 & 0 & -0.130 & 6715.190 \\
\hline 30 & 7.69 & 9.9597 & 5270.161 \\
\hline 60 & 27.8379 & 15.287 & 1845.7815 \\
\hline 90 & 52.511 & 15.415 & -1505.959 \\
\hline 120 & 73.837 & 11.413 & -3319.750 \\
\hline 150 & 87.367 & 5.818 & -3676.801 \\
\hline 180 & 92 & 0.130 & -3615.872 \\
\hline 210 & 87.756 & -5.592 & -3720.440 \\
\hline 240 & 74.369 & -11.2821 & -3395.44 \\
\hline 270 & 53.289 & -15.415 & -1593.359 \\
\hline 300 & 28.512 & -15.417 & 1770.090 \\
\hline 330 & 8.082 & -9.822 & 5226.460 \\
\hline 360 & 0 & -0.130 & 6715.190 \\
\hline & & & \\
\hline
\end{tabular}

\subsection{Indicator Diagram}

On the volume line, A piece of line $\mathrm{AB}$ corresponding to swept volume of cylinder. Then the volume which corresponding to the volume of combustion chamber is determine

$\mathrm{V}_{\mathrm{c}}=\frac{\mathrm{AB}}{\mathrm{r}^{\mathrm{c}-1}}$

$\tan \beta_{1}=(1+\tan \alpha)^{\mathrm{n} 1}-1$

$\tan \beta_{1}=(1+\tan \alpha)^{\mathrm{n} 2}-1$

where,

$\mathrm{n}_{1}$ and $\mathrm{n}_{2}$ are polytropic exponents of compression and expansion respectively

where,

$\mathrm{V}_{\mathrm{c}}=$ clearance volume

From Figure 2 ,construct a table, which express the relationship of the crank angle and the gas pressure in the step up of 30 can be calculated.The developed indicated diagram is shown in followed.

\subsection{Force acting on a crankshaft}

The forces on the crank gear are divided into the force of gas pressure in the cylinder, the forces of inertia of the moving parts in the mechanism, and the inertia and centrifugal forces of the rotating parts. The gas pressure forces are the principal forces at low engine speeds, but the inertia force may be considerably larger at high speeds. The centrifugal force also increases rapidly with an increase in speed. The pressure of gas in the engine cylinder creates the force applied to the cylinder head. This force is directed along the cylinder axis and it is equal in magnitude and opposite in direction to the force acting on the piston. The force of gas pressure in the cylinder is determine by

$\mathrm{P}_{\mathrm{G}}=\left(\mathrm{P}_{\mathrm{g}}-\mathrm{P}_{\mathrm{o}}\right) \cdot \mathrm{A}_{\mathrm{p}}$

where,

$\mathrm{P}_{\mathrm{G}}=$ force of the gas pressure
$\mathrm{A}_{\mathrm{p}}=$ area of the piston

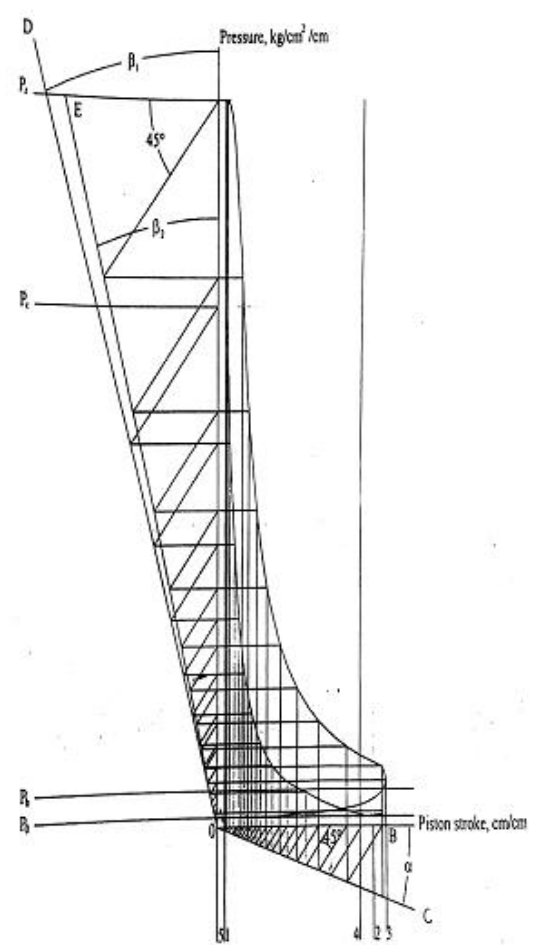

Figure 2. Indicator Diagram for vertical axis is pressure and horizontal axis is piston stroke.

Table 2. Gas pressure of various crank angles

\begin{tabular}{|c|c|}
\hline Degree & Gas Pressure $\left(\mathrm{kg} / \mathrm{cm}^{2}\right)$ \\
\hline 0 & 1.133 \\
\hline 30 & 0.97275 \\
\hline 60 & 0.86055 \\
\hline 90 & 0.6908 \\
\hline 120 & 0.7055 \\
\hline 150 & 0.8819 \\
\hline 180 & 0.9001 \\
\hline 210 & 0.9259 \\
\hline 240 & 1.204425 \\
\hline 270 & 1.87517 \\
\hline 300 & 3.35702 \\
\hline 330 & 12.38406 \\
\hline 360 & 65.7187 \\
\hline
\end{tabular}

\subsection{Inertia force}

To determine the force of inertia, it is necessary to know the masses of crank gear elements. To simplify the calculations, the actual crank gear is replaced by a dynamically equivalent system of lumped masses. All the moving parts are divided into the groups with respect to the nature of their motion. They are,

(i) Parts reciprocating along the cylinder axis (piston group)

The mass of piston with piston rings assumed to be assumed to be lumped on the piston pin axis and is designated by, $\mathrm{m}_{\mathrm{p}}$.

(ii) Rotating parts of the crankshaft

Their mass are replaced by a mass reduced to the crank radius $\mathrm{R}$ and are designated by $\mathrm{m}_{\mathrm{R}}$. This reduction is so performed as to ensure quality between the centrifugal force of inertia of the actual masses and that of reduced mass. 
The mass of the crank pin $\mathrm{m}_{\mathrm{cp}}$ with adjacent parts of the webs( $\mathrm{a}$ is assumed to be lumped along the center of the crank pin axis and, since its center of the gravity is at a distance $\mathrm{R}$ from the shaft axis, this must need not be reduced.
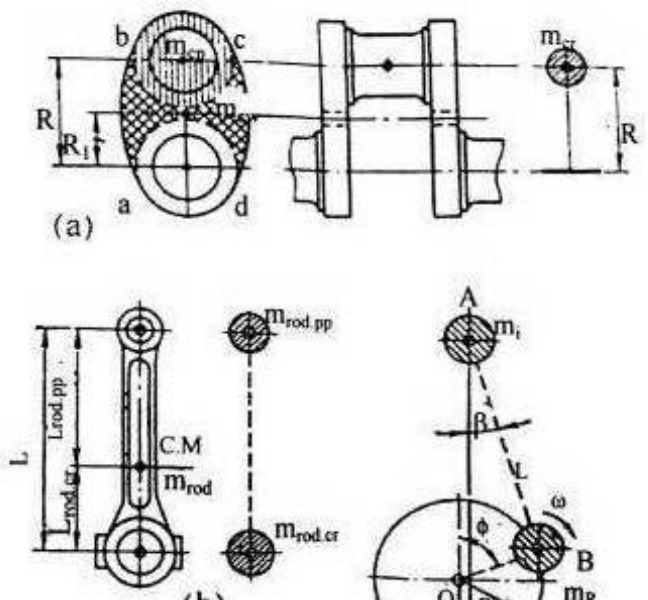

(b)

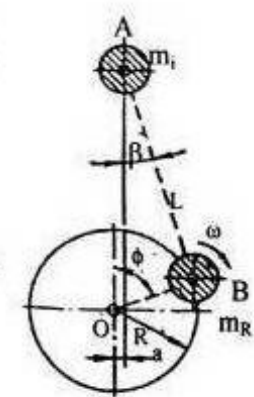

(c)

Figure 3. Reduction of the crank gear system to a two-mass one.[1]

The mass $\mathrm{m}_{\mathrm{cw}}$ of the middle portion of the crank web over the countour "abcd" with its center of gravity on the radius is reduced to the radius $R$.

$$
\begin{aligned}
& \mathrm{m}_{\mathrm{cw}} \mathrm{R}_{1} \omega^{2}=\left(\mathrm{m}_{\mathrm{cw}}\right)_{\mathrm{R}} \mathrm{R} \omega^{2} \\
& \left(\mathrm{~m}_{\mathrm{cw}}\right)_{\mathrm{R}}=\mathrm{m}_{\mathrm{cw}} \mathrm{R}_{1} / \mathrm{R}
\end{aligned}
$$

Therefore the reduced mass of the crank is,

$$
\mathrm{m}_{\mathrm{cr}}=\mathrm{m}_{\mathrm{cp}}+2\left(\mathrm{~m}_{\mathrm{cw}}\right) \mathrm{R}=\mathrm{m}_{\mathrm{cp}}+2 \mathrm{~m}_{\mathrm{cw}} \mathrm{R}_{1} / \mathrm{R}
$$

(iii) Parts performing complex plane-parallel motion space (connecting rod group).The connecting rod is replaced with a certain approximation by a system of two masses statically equivalent to its mass-the mass $\mathrm{m}_{\text {rod.pp }}$ lumped on the piston pin axis, and the mass $\mathrm{m}_{\text {rod.cr }}$ the axis of the crankpin.For this purpose, the mass of the connecting rod $\mathrm{m}_{\mathrm{rod}}$ is divided into two masses that referred to the piston pin axis.

$$
\mathrm{m}_{\text {rod.pp }}=\mathrm{m}_{\text {rod }} \mathrm{L}_{\text {roder }} / \mathrm{L}_{\text {rod }}
$$

and, that referred to the crank axis,

$$
\mathrm{m}_{\text {rod.cr }}=\mathrm{m}_{\text {rod }} \mathrm{L}_{\text {rodpp }} / \mathrm{L}_{\text {rod }}
$$

According to the statistical data, for most design of engine,

$$
\mathrm{m}_{\text {rod.pp }}=(0.2 \text { to } 0.3) \mathrm{m}_{\text {rod }}
$$$$
\mathrm{m}_{\text {rod.cr }}=(0.7 \text { to } 0.8) \mathrm{m}_{\text {rod }}
$$

Thus, the entire crank gear is replaced by a system of two lumped masses connected by rigid weight less linksthe reciprocating mass at point $\mathrm{A}$,

$$
\mathrm{m}_{1}=\mathrm{m}_{\mathrm{p}}+\mathrm{m}_{\text {rod.pp }}
$$

where, $\mathrm{m}_{\text {rod.pp }}=$ mass of connecting rod referred to piston pin and the rotating mass at point $\mathrm{B}$,

$$
\mathrm{m}_{\mathrm{R}}=\mathrm{m}_{\mathrm{cr}}+\mathrm{m}_{\text {rod.cr }}
$$
crank pin.

where, $\mathrm{m}_{\text {rod.cr }}=$ mass of connecting rod referred to

The value of $\mathrm{m}_{\mathrm{pp}}$ and $\mathrm{m}_{\mathrm{rod}}$ are selected according to data of available designs. The design masses of crank gear elements referred to one unit area of piston $A_{p}$ are given in Table.
Table 3.Design Masses of Crank Gear Elements $\left(\mathrm{g} / \mathrm{cm}^{2}\right)$

\begin{tabular}{|c|c|c|}
\hline Type of Engine & $\begin{array}{c}\text { Mass of Piston } \\
\text { from aluminum } \\
\text { alloy } \mathrm{m}_{\mathrm{p}}{ }^{\prime}\end{array}$ & $\begin{array}{c}\text { Mass of } \\
\text { connecting rod } \\
\mathrm{m}_{\text {rod }}{ }^{\prime}\end{array}$ \\
\hline $\begin{array}{c}\text { Carburetor } \\
\text { engines }(\mathrm{D}=60 \text { to } \\
100 \mathrm{~mm})\end{array}$ & $10-15$ & $12-20$ \\
\hline $\begin{array}{c}\text { Diesel engines } \\
(\mathrm{D}=80 \text { to } 120 \mathrm{~mm})\end{array}$ & $20-30$ & $25-35$ \\
\hline
\end{tabular}

The mass of piston group,

$\mathrm{m}_{\mathrm{p}}=\mathrm{m}_{\mathrm{p}} " \times \mathrm{A}_{\mathrm{p}}$

The mass of connecting rod

$\mathrm{m}_{\text {rod }}=\mathrm{m}_{\text {rod }} \times \mathrm{A}_{\mathrm{p}}$

where, $\mathrm{m}_{\mathrm{p}}=$ mass of piston

$\mathrm{m}_{\text {rod }}=$ mass of connecting rod

According to the statistical data, for most design of engine

$\mathrm{m}_{\text {rod pp }}=(0.2 \sim 0.3) \mathrm{m}_{\text {rod }}$

$\mathrm{m}_{\text {rod cr }}=(0.7 \sim 0.8) \mathrm{m}_{\text {rod }}$

The entire crank gear is replaced by a system of two lumped masses connected by rigid weightless links the reciprocating mass at point $\mathrm{A}$,

$\mathrm{m}_{1}=\mathrm{m}_{\mathrm{p}}+\mathrm{m}_{\mathrm{rod} p}$

Force of inertia $\left(\mathrm{F}_{\mathrm{i}}\right)$ included by reciprocating mass is determined.

$\mathrm{F}_{\mathrm{i}}=-\mathrm{m}_{\mathrm{i}} \mathrm{R} \omega^{2}(\cos \Phi+\lambda \cos 2 \Phi+\mathrm{k} \lambda \sin \Phi)$

The rotating mass at $\mathrm{pt} B$

$\mathrm{m}_{\mathrm{R}}=\mathrm{m}_{\mathrm{cr}}+\mathrm{m}_{\mathrm{rod} \mathrm{cr}}$

The gas pressure force and the inertia force may be combined algebraically to determine the net force acting along the cylinder axis.Force acting toward the crank shaft are plotted as positive values. Thus ,only the induction and the first part of the compression stroke will have negative value.The inertia forces are always negative at the top and positive at the bottom of the stroke.The net force acting along the cylinder axis can be determined by

$\mathrm{F}=\mathrm{P}_{\mathrm{G}} \pm \mathrm{F}_{\mathrm{i}}$

At various crank angle $\Phi$, the gas pressure force $\mathrm{P}_{\mathrm{G}}$, the inertia force $F_{i}$ and the net force $F$ are change or various with their corresponding crank angle and presented in Table 3.

Table 4.Gas pressure force of various crank angle

\begin{tabular}{|c|c|c|c|}
\hline Degree, $\phi$ & $\begin{array}{c}\text { Gas Pressure } \\
\text { Force, } \mathrm{P}_{\mathrm{G}}, \mathrm{kg}\end{array}$ & $\begin{array}{c}\text { Inertia } \\
\text { Force, } \mathrm{F}_{\mathrm{I}}, \mathrm{kg}\end{array}$ & $\begin{array}{c}\text { Net Force, } \mathrm{F} \\
\mathrm{kg}\end{array}$ \\
\hline 0 & 7.591 & -1056.098 & -1048.506 \\
\hline 30 & -1.1829 & -828.833 & -830.017 \\
\hline 60 & -7.959 & -290.643 & -298.602 \\
\hline 90 & -17.648 & 236.842 & 219.194 \\
\hline 120 & -16.809 & 522.097 & 505.288 \\
\hline 150 & -6.741 & 578.251 & 571.51 \\
\hline 180 & -5.702 & 568.668 & 562.966 \\
\hline 210 & -4.229 & 585.159 & 580.93 \\
\hline 240 & 11.668 & 533.736 & 545.404 \\
\hline 270 & 49.953 & 250.539 & 300.492 \\
\hline 300 & 134.536 & -278.404 & -143.868 \\
\hline 330 & 649.790 & -821.887 & 172.097 \\
\hline 360 & 3694.078 & -1356.098 & 2637.98 \\
\hline
\end{tabular}




\subsection{Piston side thrust and connecting rod force}

The net force is exerted in the direction along the cylinder axis. The angularity of the connecting rod causes the net force to be divided into two components; one producing piston thrust against the cylinder wall, and the other acting along the axis of the connecting rod.

The piston side thrust against the cylinder wall determined by

$\mathrm{Q}=\mathrm{F} \tan \beta=\mathrm{F} \lambda(\sin \Phi-\mathrm{k})$

The force along the connecting rod is determined by

$\mathrm{K}=\frac{\mathrm{F}}{\cos \beta}=\mathrm{F}\left[1+\frac{\lambda^{2}}{4}(1-\cos 2 \phi)\right]$

The tangential force at the crank pin is determined by the resolving the force along the connecting rod into two components, one acting tangentially to the crank circle at the crank pin and the other acting radially at the crank pin. The tangential force to the crank radius circle and normal force directed along the crank radius are

$\mathrm{F}_{\mathrm{t}}=\mathrm{F}\left(\sin \phi+\frac{\lambda}{2} \sin 2 \phi-\mathrm{k} \lambda \cos \phi\right)$

$\mathrm{N}=\mathrm{F}\left(\cos \phi-\frac{\lambda}{2}(1-\cos 2 \phi)+\mathrm{k} \lambda \sin \phi\right)$

A couple of force appears with a moment, $\mathrm{T}$ called the torque and is determined

$\mathrm{T}=\mathrm{F}_{\mathrm{t}} \times \mathrm{R}$

Table 5. The relation of the force $\mathrm{Q}, \mathrm{k}, \mathrm{F}_{\mathrm{t}}$ and $\mathrm{N}$

\begin{tabular}{|c|c|c|c|c|}
\hline Degree & $\begin{array}{c}\text { Side } \\
\text { Thrust } \\
\text { Force }\end{array}$ & Force & $\begin{array}{c}\text { Tangential } \\
\text { Force }\end{array}$ & $\begin{array}{c}\text { Normal } \\
\text { Force }\end{array}$ \\
\hline 0 & 8.870 & -1048.5 & 8.87 & -1048.50 \\
\hline 30 & -117.48 & -839.35 & -516.75 & -660.07 \\
\hline 60 & -75.05 & -308.68 & -296.12 & -84.29 \\
\hline 90 & 63.90 & 229.06 & 219.19 & -63.9 \\
\hline 120 & 127.00 & 522.34 & 373.91 & -362.59 \\
\hline 150 & 80.89 & 577.94 & 215.69 & -535.39 \\
\hline 180 & -4.76 & 562.06 & 4.76 & -562.96 \\
\hline 210 & -92.05 & 587.46 & -210.70 & -549.15 \\
\hline 240 & -146.31 & 563.81 & -399.18 & -399.40 \\
\hline 270 & -92.69 & 314.01 & -300.49 & -92.69 \\
\hline 300 & 38.59 & -148.72 & 143.89 & -38.50 \\
\hline 330 & 27.27 & -174.03 & 109.66 & -135.40 \\
\hline 360 & -22.32 & 2637.98 & -22.32 & 2637.98 \\
\hline
\end{tabular}

The relation of the force $\mathrm{Q}, \mathrm{k}, \mathrm{F}_{\mathrm{t}}$ and $\mathrm{N}$ are shown in Table 3 . The torque on the main journals $\mathrm{V}_{\mathrm{s}}$ the torque of the crank pin for four cylinders four-stroke engine are shown following.

Table 6. Within the crank angle of Torque

\begin{tabular}{|c|c|c|c|}
\hline Degree & Torque & Degree & Torque \\
\hline 0 & 0.40802 & 390 & 24.532 \\
\hline 30 & -23.770 & 420 & 2.699 \\
\hline 60 & -13.622 & 450 & 19.091 \\
\hline 90 & 10.084 & 480 & 23.459 \\
\hline 120 & 17.199 & 510 & 12.935 \\
\hline 150 & 9.922 & 540 & 0.278 \\
\hline 180 & 0.219 & 570 & -10.105 \\
\hline 210 & -9.692 & 600 & -18.164 \\
\hline 240 & -18.362 & 630 & -11.589 \\
\hline 270 & -13.822 & 660 & 13.042 \\
\hline 300 & 6.618 & 690 & 24.195 \\
\hline 330 & 5.044 & 720 & 0.40802 \\
\hline 360 & -1.026 & & \\
\hline
\end{tabular}

Using the data of table 5,plotted the torque on the main journals and the torque on the crank pin for a four cylinder four stroke engine is plotted. Shown in followed.
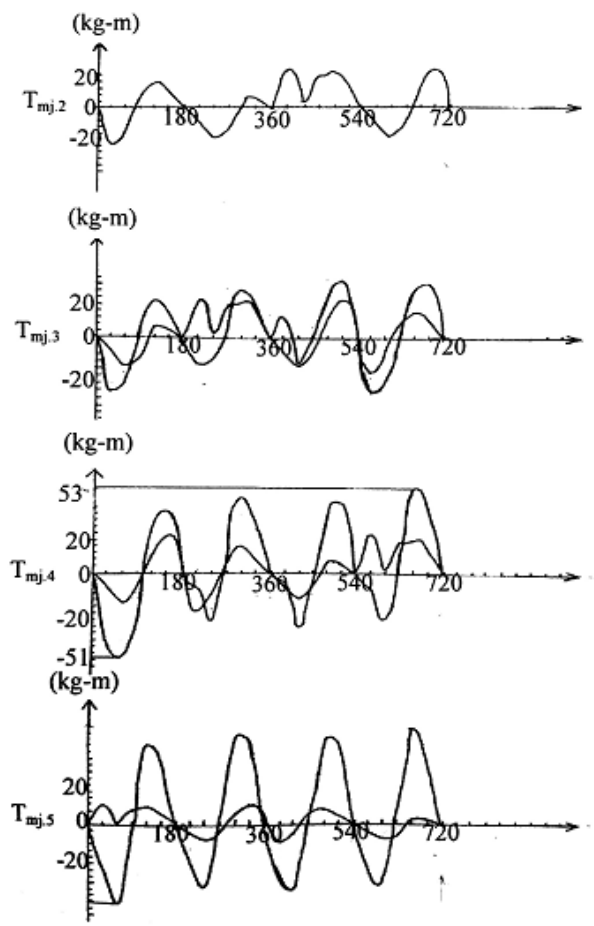

Figure 4. Accumulating torque diagram of main journal for diesel engine
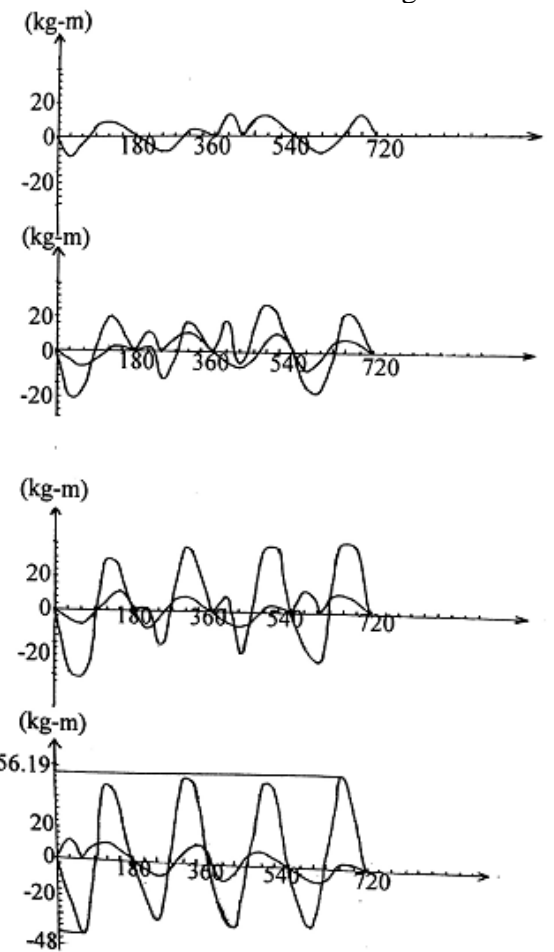

Figure 5. Accumulating torque diagram of crank pin for diesel engine. 


\section{CONCLUSION}

In this paper, the author used the double span crankshaft. In the indicated diagram calculation taken the assumed valued i.e the polytropic exponent of compression $n_{1}$ is between the range of 1.32 to 1.4 and taken as 1.32 and polytropic exponent of expansion $\mathrm{n}_{2}$ is 1.18 to 1.28 and taken as 1.18 . The mean piston speed is within the range of 5 to 9 and taken as $7 \mathrm{~m} / \mathrm{s}$. This crankshaft design is specially design for high speed light vehicles. Not only this design is economy from commercial point of view but also it can be used for prolonged time.

\section{ACKNOWLEDGMENTS}

First of all, the author is grateful to Dr Thein Gi, Rector of Technological University(Thanlyin), for giving the permission to submit the paper.

The author wishes to express his heartfelt thanks to each and every one who assisted in completing this paper.

Finally, the author deep gratitude and appreciation go to his parents for his moral supports, patience, understanding and encouragement.

\section{REFERENCES}

[1] M.KHOVAKH, 1979: Motor Vehicle Engines, MIR Publisher-Moscow.

[2] Charles Fayette Taylor, 1960: The Internal-Combustion Engine in Theory and Partice. The Technology Press of The Massachusetts Institute of Technology and John Wiley and Sons,Inc.

[3] George H.Martin,1969: Kinematic and Dyanmics of Machines. McGraw- Hill Book Company,Inc

[4] Ray H.Bacom,1968: The car Engine and Structure Macmillan \& Cleaver.

[5] Malee,v.L 1945: Internal Combustion Engine, Tokyo.

[6] H.F.P Purday, 1962: Diesel Engine Designing. Constable \& Company Ltd.

[7] A.T.J.Kersey,1947: Internal-Combustion Engineering. Third Edition, Blackie and Son Limited

[8] RobertL.Streeter, 1915: Internal Combustion Engine (Theory and Design). First Edition, McFraw-Hill Book Company, Inc. 